Part of Journal of Research of the National Bureau of Standards, Volume 24, May 1940

\title{
FRICTION AND TEMPERATURE AS CRITERIA FOR SAFE OPERATION OF JOURNAL BEARINGS
}

\author{
By Samuel A. McKee
}

\section{ABSTRACT}

This paper describes a method for the application of friction and heat-dissipation data to the determination of the load-carrying capacity of a journal bearing when operating with a lubricant of known characteristics. This method depends upon two considerations: First, that the bearing shall operate in the region of stable lubrication; and second, that the operating temperature shall not exceed some limiting value.

The relationship between the thermodynamic and hydrodynamic factors pertaining to journal-bearing lubrication is given by an equation for thermal equilibrium. From this relation, pressure-speed curves representing the limits for safe operation for a given bearing with a given lubricant are obtained by consideration of permissible values for temperature rise and the operating variable $Z N / P$, where $Z$ is the viscosity of the oil, $N$ the speed of the journal, and $P$ the bearing pressure.

An example of the application of this method is given, using friction and heatdissipation data obtained experimentally in laboratory apparatus with bearings and lubricant typical of some automotive installations. Curves showing the loadcarrying capacity and typical operating characteristics are given for this bearing and lubricant. The method is used also to calculate the effects upon the loadcarrying capacity of this bearing of changes in the viscosity characteristics of the lubricant, critical $Z N / P$ value, ambient temperature, and heat-dissipation characteristics. The practical application of the method as a means for estimating the load-carrying capacity of bearings in actual service is outlined for the case of automotive-engine bearings.

\section{CONTENTS}

List of symbols

I. Introduction $\ldots$

II. Equations for thermal equilibrium

III. Method for determination of load-carrying capacity _. . . . . _ 494

IV. Operating characteristics in the stable region _........ 498

V. Effect of viscosity characteristics of the oil used

VI. Effects of changes in critical $Z N / P$ value _..._.

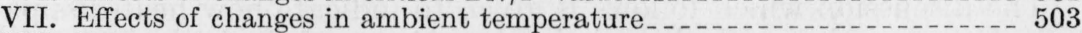

VIII. Effects of changes in heat-dissipation characteristics ............. 504

IX. Comparison with pressure-velocity $(P V)$ relation $\ldots$

$\mathrm{X}$. Application of method to automotive-engine bearings_........... 507

XI. Conclusion

XII. References_... 508

\section{LIST OF SYMBOLS}

$D=$ Journal diameter, in.

$L=$ Bearing length, in.

$C=$ Running clearance (difference between bearing diarneter and journal diameter), in.

$W=$ Total load acting on bearing, lb.

$P=W / L D=$ Pressure on projected area of bearing, $\mathrm{lb} / \mathrm{in}^{2}$

$N=$ Speed of journal, rpm. 
$V=\pi D N / 12(60)=$ Peripheral velocity of journal, $\mathrm{ft} / \mathrm{sec}$.

$Z=$ Absolute viscosity of lubricant at atmospheric pressure and bearing temperature, centipoises.

$F=$ Tangential frictional force, $\mathrm{lb}$.

$f=F / W=$ Coefficient of friction.

$H=$ Heat generated in bearing per unit time, commonly expressed in Btu/min but here converted to in. $1 \mathrm{~b} / \mathrm{min} .^{1}$

$H^{\prime}=$ Heat dissipated by bearing per unit time, in. lb/min.

$T_{B}=$ Bearing temperature, ${ }^{\circ} \mathrm{F}$.

$T_{0}=$ Ambient temperature, ${ }^{\circ} \mathrm{F}$.

$\Delta T=T_{B}-T_{0}=$ Temperature rise, ${ }^{\circ} \mathrm{F}$.

$k=$ Coefficient in eq $1=473 \times 10^{-10}$.

$\Delta f=$ Correction term constant for a given bearing (see reference [5]).

$U=A$ coefficient of heat transfer.

$a=$ Exponent in eq 3 .

$\mathrm{SUV}=$ Saybolt universal viscosimeter

$\mathrm{VI}=\mathrm{Viscosity}$ index.

\section{INTRODUCTION}

One of the chief limitations of the science of journal-bearing lubrication in its present status is the difficulty of applying the results of experimental and analytical investigations directly to problems involving the performance of bearings in actual service. Research of inestimable value has provided a reasonably workable knowledge of the hydrodynamies of the load-carrying oil film, but this information in itself cannot answer the question so pertinent to the engineer, namely, "How much load can this bearing safely carry when operating at a given speed with a given lubricant?" Probably the most common cause of failure to answer this question is the present lack of information pertaining to the thermodynamics of journal-bearing lubrication.

The heat generated in shearing the film of lubricant in a journal bearing produces a rise in temperature. This rise has two major effects upon the performance of the bearing: first, it increases the rate of heat-dissipation; and second, it decreases the viscosity of the lubricant. In the region of stable lubrication this decrease in viscosity decreases the rate of heat generation, and the bearing will come to equilibrium at the temperature where the rates of heat generation and dissipation are equal. The performance of the bearing, therefore, is dependent not only upon the hydrodynamics of the oil film but also upon the heat-dissipation characteristics of the bearing.

The discussion which follows is given to indicate how heat-dissipation data, together with the existing knowledge of the hydrodynamics of the oil film, may be used to provide, with some degree of accuracy at least, an answer to the question mentioned above and also to estimate the effects on the load-carrying capacity of the bearing of changes in a number of the various factors involved in journal-bearing lubrication.

Some of the fundamental concepts of this method for determining load-carrying capacity have been discussed in detail in a previous publication [1]. ${ }^{2}$ A relationship between the thermodynamic and hydrodynamic factors pertaining to journal-bearing lubrication was developed by consideration of a state of thermal equilibrium and a

1 When all quantities of energy are expressed in the same unit, inch pounds in this case, the numerical factor known as "the mechanical equivalent of heat" does not appear in the equations.

2 Figures in brackets indicate the literature references at the end of this paper. 
criterion for safe operation was suggested. This criterion involves two primary considerations: First, that the bearing shall always operate in the region of stable lubrication; and second, that the operating temperature of the bearing shall never exceed some limiting value. The criterion for operation in the region of stable lubrication may be obtained either from data and computations pertaining to the minimum thickness of the oil film [2] or from the frictional characteristics of the bearing. Of these, the second method lends itself more readily to the particular purpose, since the rate of heat generation and consequently the operating temperature are also dependent upon the frictional characteristics of the bearing.

The usual method for indicating the frictional characteristics of a journal bearing is by plotting $f$, the coefficient of friction, against the generalized operating variable $Z N / P$, the product of the viscosity of the lubricant by the speed of the journal divided by the load per unit projected area. A number of publications [3, 4] have indicated the justification for the use of this curve and have also pointed out its significance in determining the region of stable lubrication. In a typical $[f, Z N / P]$ curve, $f$ passes through a minimum usually at some relatively low value of $Z N / P$. At values of $Z N / P$ above this minimum $f$ decreases with a decrease in $Z N / P$, whereas at values below the minimum there is a rapid increase of $f$ with decrease in $Z N / P$.

From the preceding discussion regarding thermal equilibrium, it is seen that conditions are unstable at values of $Z N / P$ below the minimum point. In this region the rate of heat generation will increase more rapidly with a rise in temperature than the rate of heat dissipation. On the other hand, at values of $Z N / P$ above the minimum point, a rise in temperature will decrease the rate of heat generation, which, with the increase in the rate of heat dissipation, will cause the bearing to reach thermal equilibrium. This region is commonly known as the region of stable lubrication. One criterion for safe operation in the region of stable lubrication may, therefore, be defined by a minimum limiting value of $Z N / P$.

\section{EQUATIONS FOR THERMAL EQUILIBRIUM}

Experimental data [5] indicate that in the region of stable lubrication the frictional characteristics of journal bearings may be represented with reasonable accuracy by an equation of the form

$$
f=k(Z N / P)(D / C)+\Delta f
$$

using the nomenclature given in the list of symbols. In this equation $k$ is constant for all bearings and is equal to $473 \times 10^{-10}$ when using the given units. $\Delta f$ is constant for a given bearing, but varies for bearings of different length-diameter ratios. Information regarding $\Delta f$ has been given in greater detail in a previous publication [5]. The rate of heat generation in these bearings, therefore, may be represented by the equation

$$
H=P N D[k(Z N / P)(D / C)+\Delta f] \pi L D .
$$

The fact that there is little published information available regarding heat dissipation in bearings has already been mentioned. However, the equation

$$
H^{\prime}=U \pi L D \Delta T^{a}
$$


may be used to represent approximately such data [2, 6, 7] as are available. In this equation the coefficient $U$ and the exponent $a$ are treated as constants for a given bearing installation, but may be different for different installations. Their values will depend upon the factors governing dissipation by radiation, conduction, and convection and also upon the dissipation characteristics of the lubricating: system.

Conditions for thermal equilibrium may be represented by equating: the values of $H$ and $H^{\prime}$ to give

$$
P N D[k(Z N / P)(D / C)+\Delta f]=U \Delta T^{a} .
$$

This equation represents approximately the relation between the rise in temperature of a bearing above its surroundings and the factors affecting the hydrodynamics of the load-carrying oil film when the operation is in the region of stable lubrication, and thus provides a definite tie between the hydrodynamics and thermodynamics of journal-bearing lubrication.

\section{METHOD FOR DETERMINATION OF LOAD-CARRYING CAPACITY}

Equation 4 also contains all of the variables pertinent to the question of load-carrying capacity; namely, $N$, the speed, $P$, the load per unit projected area, $Z$, the viscosity of the lubricant, $\Delta T$, the temperature rise which determines the operating temperature, and $Z N / P$, the generalized operating variable upon which the limits of stable lubrication depend. This equation, therefore, in conjunction with a lower limiting value of $Z N / P$ to assure stable lubrication, and an upper limiting value of $\Delta T$ based upon a maximum allowable bearing temperature, together with the ambient temperature, may be used to evaluate the safe limits of load and speed for a given bearing operating with a given lubricant of known viscosity.

If it is assumed, for example, that $\bar{K}_{1}$ is the minimum value of $Z N / P$ allowable for safe operation, then

$$
Z N / P=K_{1} \text {. }
$$

By substituting $K_{1}$ for $Z N / P$, together with the values of $D, D / C$, $\Delta f$ and $U$, all of which are constant for the given bearing, eq 4 becomes

$$
P N=K_{2} \Delta T^{a} \text {, }
$$

where $K_{2}$ is a constant term and $a$ is a constant for the given bearing. Then for all values of $\Delta T$ at or below the upper limiting value, the limits for safe operation dependent upon the minimum $Z N / P$ value are defined by the two eq 5 and 6 .

Dividing eq 6 by 5 results in

$$
P=\sqrt{\frac{K_{2} Z \Delta T^{a}}{K_{1}}}
$$

and by transposition eq 5 becomes

$$
N=\frac{K_{1} P}{Z} .
$$


For any given value of $\Delta T$, eq 7 and 8 may be used to obtain the limiting values of $P$ and $N$, since the value of $Z$ for the given temperature may be determined from data on the viscosity of the lubricant.

Under certain conditions of high-speed operation of the bearing, the value of $Z N / P$ may be greater than the critical value, but the rate of heat generation is sufficiently high to make the maximum allowable value of $\Delta T$ the limiting factor. The equation defining the safe limits under these conditions may be obtained from eq 4, which for a given bearing assumes the form

$$
b P N[m(Z N / P)+\Delta f]=U \Delta T^{a},
$$

where $b, m, \Delta f, U$, and $a$ are constant terms.

By expanding and transposing this becomes

$$
P=\frac{K_{3} \Delta T^{a}}{N}-K_{4} Z N
$$

$K_{3}$ and $K_{4}$ being constants.

The limiting values of $P$ for a given $N$ may be obtained by substituting in eq 10 the particular value of $N$, together with the limiting value of $\Delta T$, the corresponding value of $Z$, and the value of $a$ for the given bearing.

Thus the boundary between safe and unsafe operation, as defined by the assumed conditions for the given bearing and lubricant, may be indicated graphically by plotting the various values of $P$ against their corresponding values of $N$ as determined by the use of eq 7, 8, and 10 . In this connection it should be noted that the values obtained from eq 7 and 8 are applicable only when $\Delta T$ is at or below the critical value and those obtained from eq 10 only when $Z N / P$ is equal to or greater than the critical value.

Recently some information has been obtained at the National Bureau of Standards on the operating characteristics of journal bearings. Sufficient data were taken over a range of speeds from 1,000 to $3,000 \mathrm{rpm}$ to determine the frictional characteristics and the heatdissipation characteristics in the region of stable lubrication and also the critical $Z N / P$ value for operation in the stable region. Hence these data may be used to illustrate the application of eq 7, 8, and 10 .

The following are the data pertaining to the construction and operating charateristics of these bearings:

Apparatus: 4-bearing friction machine, bearings enclosed in case.

Operation: constant speeds at a number of loads, direction of load constant relative to bearings.

Type of bearings: $360^{\circ}$ solid sleeves.

Bearing material: copper-lead lining, steel backing.

Nominal dimensions: $D=2$ in., $L=1 \frac{11 / 4}{4}$ in., $D / C=500$.

Lubricating system: forced feed, 80 to $85 \mathrm{lb} / \mathrm{in}^{2}{ }^{2}$ oil pressure, oil fed to bearings through center of shaft.

Lubricant: mineral aviation oil, 124.4 sec SUV at $210^{\circ} \mathrm{F}$, viscosity index $=98$.

Friction constants: $k=473 \times 10^{-10}, \Delta f=0.0023$ (from $[f, Z N / P]$ curve based on observed data).

Point of minimum $f: Z N / P=4.6$ (from $[f, Z N / P]$ curve, bearings fairly well run in).

Heat-dissipation constants: $U=7.38, a=1.65$ (from observed data). 
Ambient temperature: $80^{\circ} \mathrm{F}$ (average).

Maximum allowable bearing temperature: $360^{\circ} \mathrm{F}$ (assumed) hence, maximum allowable $\Delta T=280^{\circ} \mathrm{F}$.

The particular value chosen for maximum allowable bearing temperature has no special significance, although it possibly approaches the upper limits for aircraft-engine operation.

By the substitution of the values of the constants as defined by these data, eq 7, 8, and 10 become, respectively,

$$
\begin{aligned}
P & =\sqrt{334 Z \Delta T^{1.65}} \\
N & =\frac{4.6 P}{Z}
\end{aligned}
$$

and

$$
P=\frac{1,605 \Delta T^{1.65}}{N}-0.0103 Z N
$$

and may be used directly to compute the limiting values of $P$ and $N$.

The results of these computations are shown graphically in figure 1.

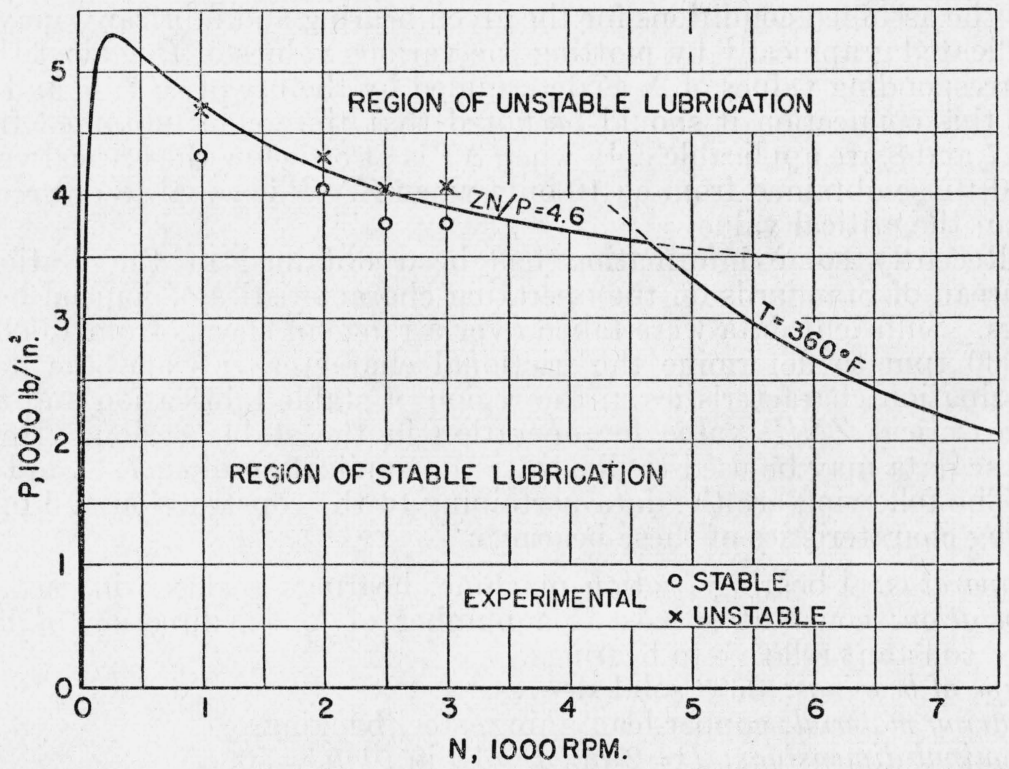

FigURE 1.-Curves showing permissible pressures for safe operation at various speeds.

$2 \times 1 \frac{1}{4}$ in. test bearings; ambient temperature, $80^{\circ} \mathrm{F}$; a viation oil $124.4 \mathrm{sec} \mathrm{SUV}$ at $210^{\circ} \mathrm{F}, 98 \mathrm{VI}$ (SAE 60 ); limitations, $Z N / P>4$.6; temperature, $<360^{\circ} \mathrm{F}$.

The curve $Z N / P=4.6$ is derived from eq 7 and 8 and represents the maximum permissible pressures for safe operation over the range of speeds where the minimum permissible value of $Z N / P$ is the limiting factor. The curve $T_{B}=360^{\circ} \mathrm{F}$ is derived from eq 10 and represents the pressure limitations based upon the assumed limiting operating 
temperature. Thus the region below the solid curves represents conditions of safe operation under the assumed limitations.

In the experimental work with these bearings, test runs were made at various constant speeds and the loads were increased by arbitrary amounts until the bearings reached the unstable region. Data obtained in these tests are also plotted in figure 1. The circles represent loads and speeds at which the bearings operated in the stable region, whereas the crosses represent the loads and speeds at which the operation was in the unstable region. It will be noted that in the range covered, the experimental data and the curves are in agreement within experimental error.

In considering these curves from the standpoint of bearing operation, it is seen that for speeds above $300 \mathrm{rpm}$ the permissible load for

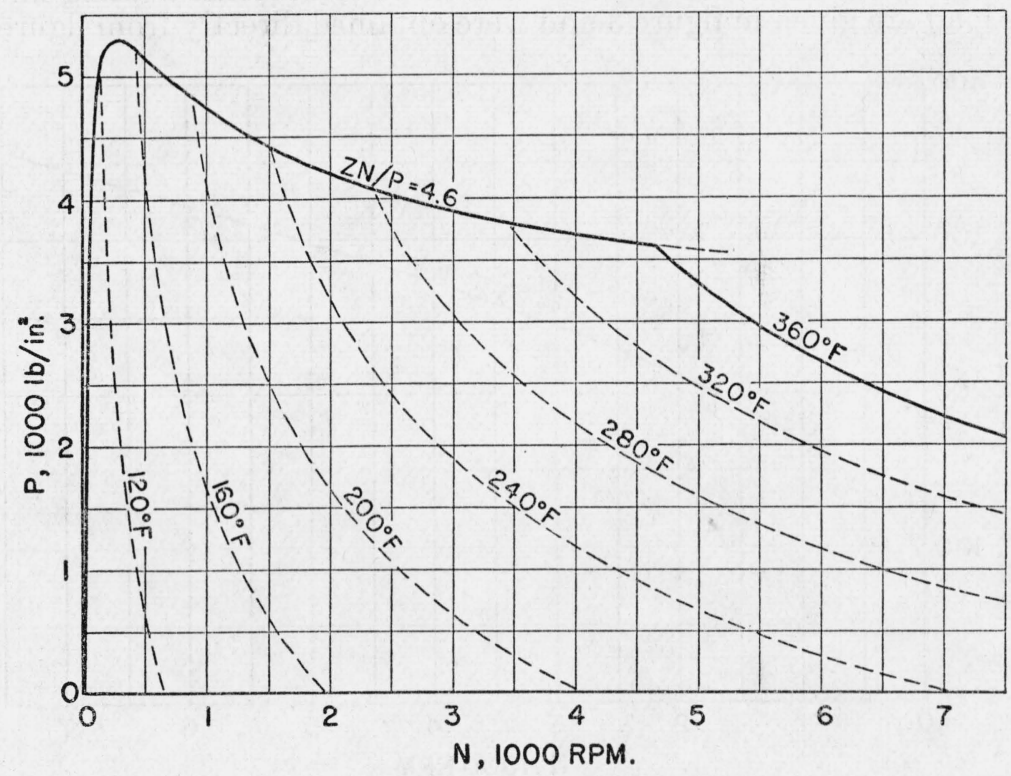

FIgURE 2.-Lines of constant temperature in region of stable lubrication.

$2 \times 1 \frac{1}{4}$ in. test bearings; ambient temperature, $80^{\circ} \mathrm{F}$; aviation oil $124.4 \mathrm{sec}$ SUV at $210^{\circ} \mathrm{F}, 98 \mathrm{VI}$ (SAE 60 ).

these bearings decreases with an increase in speed. This is of interest in that it is exactly opposite from what would be expected if temperature effects were ignored and only the hydrodynamic considerations taken into account.

Besides providing a means for obtaining limits based on a maximum permissible temperature, eq 10 may also be used to determine lines of constant temperature on the load-carrying capacity chart. Such lines for various constant temperatures are shown in figure 2. These lines may be used to show that if the curves derived from eq 7,8 , and 10 represent the limits of safe operation, all points below them are in this region of safety. For example, if $P^{\prime}$ represents any value of $P$ lying on these curves and $N^{\prime}$ the corresponding value of $N$, then by interpolation from the lines of constant temperature it will be seen that if $N$ equals $N^{\prime}$ and $P$ is less than $P^{\prime}$, the equilibrium temperature 
of the bearing will be decreased; hence the temperature at $N^{\prime} P$ will be less than the limiting temperature. This decrease in temperature will cause an increase in $Z$. With $Z$ increased and $P$ decreased and $N$ remaining constant, the value of $Z N / P$ will be greater than the limiting value; hence the bearing will be operating in the safe region.

\section{OPERATING CHARACTERISTICS IN THE STABLE REGION}

The constant temperature lines in figure 2 may be used also to determine the operating characteristics of the bearing at any point in the stable region. Suppose, for example, that the bearing is operating with the same lubricant at a constant load such that $P$ equals 2,000 $\mathrm{lb} /$ in. $^{2} \quad$ The temperature-speed characteristics for the bearing under this load are given in figure 3 and were obtained directly from figure 2.

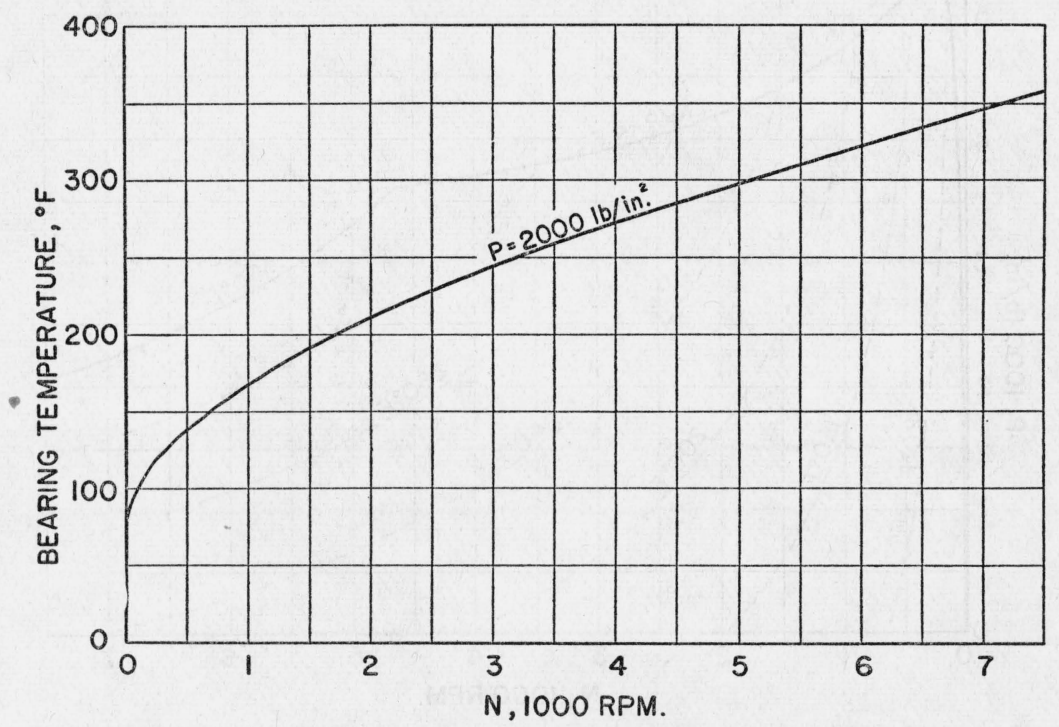

FIGURE 3.-Temperature-speed curve for $2 \times 1 \frac{1}{4}$ in. test bearings.

Constant load $\left(P=2,000 \mathrm{lb} /{ }^{2} .^{2}\right)$; ambient temperature, $80^{\circ} \mathrm{F}$; aviation oil $124.4 \mathrm{sec} \mathrm{SUV}$ at $210^{\circ} \mathrm{F}, 98 \mathrm{VI}$, (SAE 60).

The values of $Z N / P$ for various speeds when operating at this load may be computed from figure 3 and the values of $Z$ at the various temperatures. This curve is shown in figure 4. It is of interest that this curve indicates that for speeds above $700 \mathrm{rpm}$ the value of $Z N / P$ decreases with an increase in $N$, whereas in the hydrodynamic relation, if temperature effects are neglected, $Z N / P$ is directly proportional to $N$.

The frictional horsepower-speed curve given in figure 5 is obtained from figure 3 and eq 3 . This curve is of interest in that the increase in horsepower with increase in speed is less than the first power of the speed while from hydrodynamics alone the horsepower might be expected to be proportional to the square of the speed. Similar 


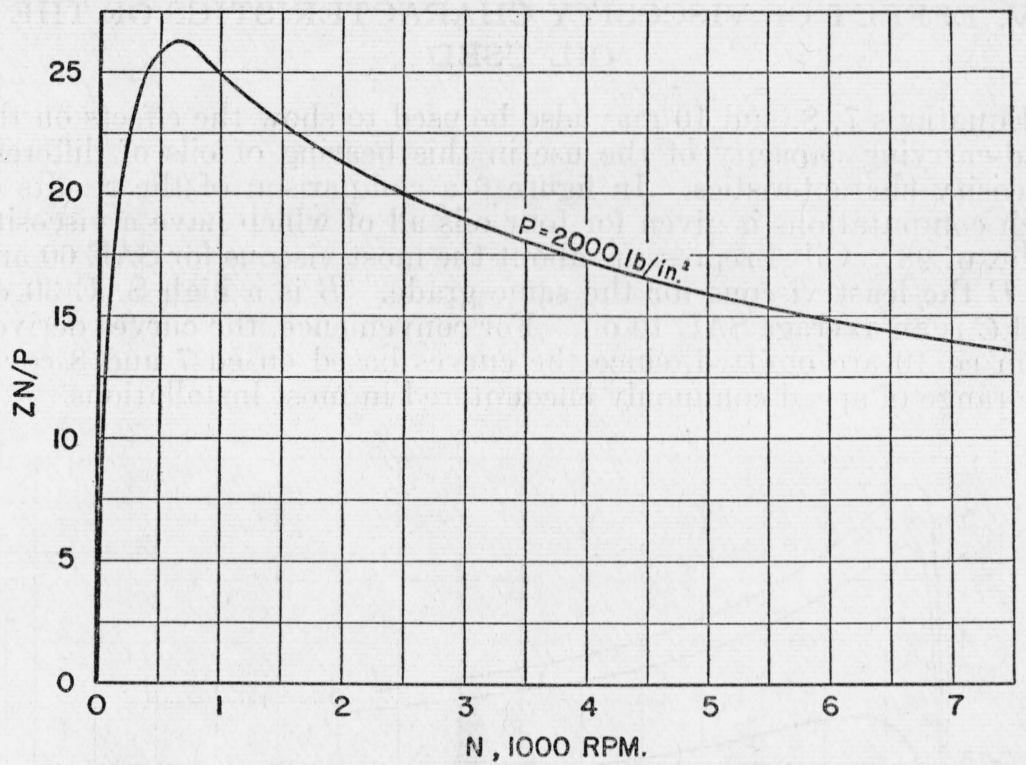

FIGURE 4. $-Z N / P$-speed curve for $2 \times 1 \frac{1}{4}$ in. test bearings.

Constant load $\left(P=2,000 \mathrm{lb} /\right.$ in..$\left.^{2}\right)$; ambient temperature, $80^{\circ} \mathrm{F}$; aviation oil $124.4 \mathrm{sec} \mathrm{SUV}$ at $210^{\circ} \mathrm{F}, 98 \mathrm{VI}$, (SAE 60).

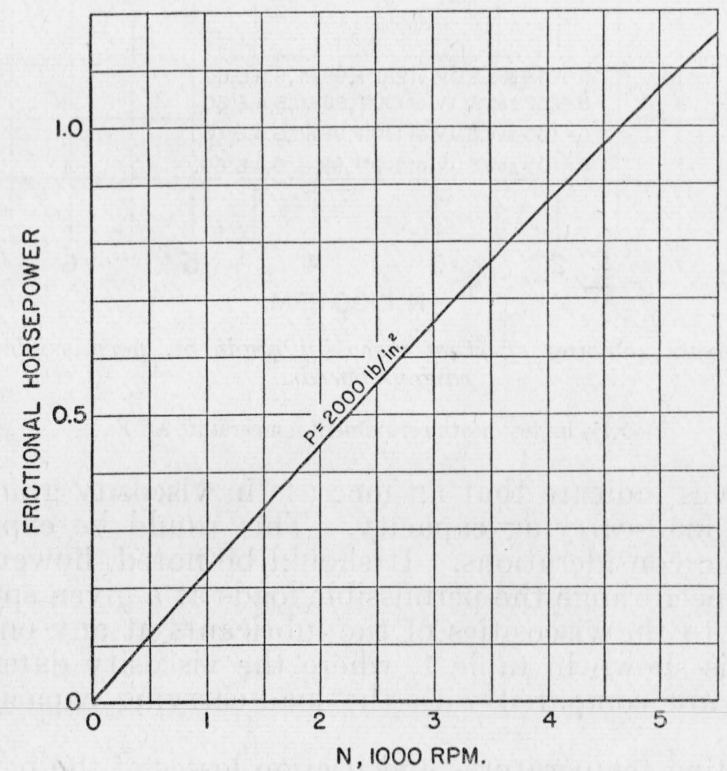

FIGURE 5.-Frictional horsepower-speed curve for $2 \times 1 \frac{1}{4} \mathrm{in}$. test bearings.

Constant load $\left(P=2,000 \mathrm{lb} / \mathrm{in}^{2}\right)$; ambient temperature, $80^{\circ} \mathrm{F}$; aviation oil $124.4 \mathrm{sec} \mathrm{SUV}$ at $210^{\circ} \mathrm{F}, 98 \mathrm{VI}$, (SAE 60).

curves showing the operating characteristics of the bearing with this lubricant might be drawn for other constant loads or for various constant speeds with varying loads. 


\section{EFFECT OF VISCOSITY CHARACTERISTICS OF THE OIL USED}

Equations 7, 8, and 10 may also be used to show the effects on the load-carrying capacity of the use in this bearing of oils of different viscosity characteristics. In figure 6 a comparison of the results of such computations is given for four oils all of which have a viscosity index of 98. Oil $A$ represents about the most viscous for SAE 60 and oil $D$ the least viscous for the same grade. $B$ is a high SAE 30 oil and $C$ is an average SAE 10 oil. For convenience, the curves derived from eq 10 are omitted, since the curves based on eq 7 and 8 cover the range of speed commonly encountered in most installations.

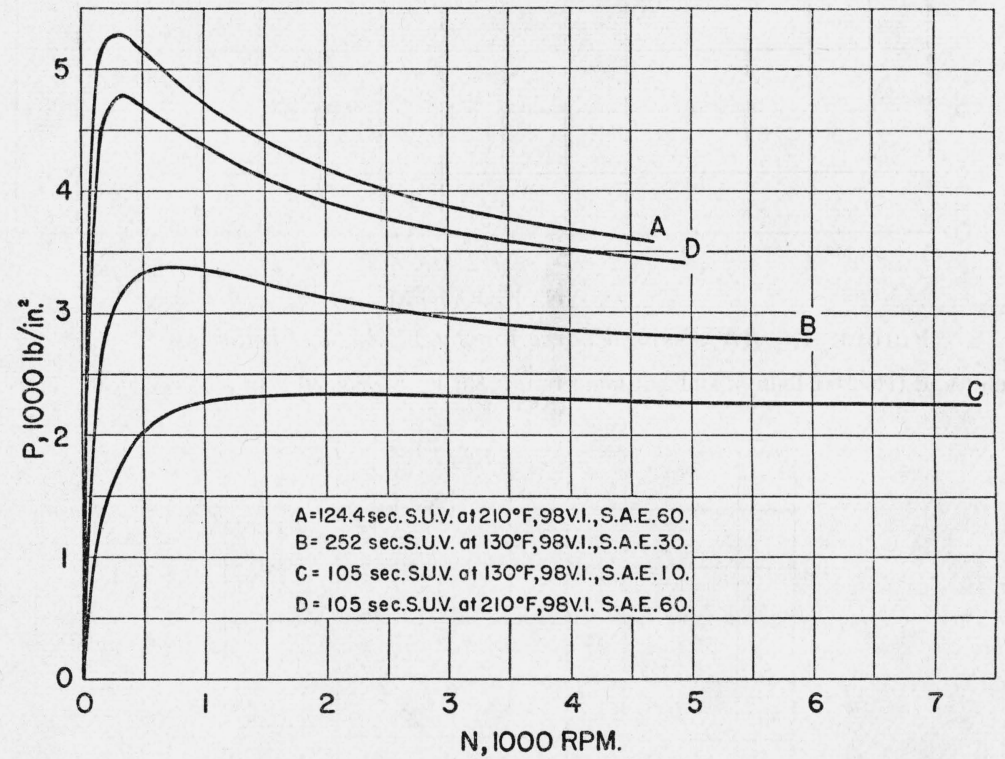

Figure 6.-Curves showing effect of viscosity grade on permissible pressures at various speeds.

$2 \times 1 \frac{1}{4}$ in. test bearings, ambient temperature $80^{\circ} \mathrm{F}$.

These curves indicate that an increase in viscosity grade tends to increase the load-carrying capacity. This would be expected from hydrodynamic considerations. It should be noted, however, that in the normal speed range the permissible loads at a given speed are not proportional to the viscosities of the lubricants at any one temperature. This is shown in table 1 , where the viscosity data at $100^{\circ} \mathrm{F}$ and $210^{\circ} \mathrm{F}$ are compared with the load-carrying capacity data at $3,500 \mathrm{rpm}$.

The operating temperatures and friction losses of the bearing when using oils of different viscosity may be obtained as described previously by developing lines of constant temperature, such as were shown in figure 2. The results of such computations for oil $C$, together with the data given in table 1 , provide a means for comparing the performance of $A$ and $C$ in this bearing. Suppose, for example. 
in a particular installation the conditions of normal operation of the bearing were $P=1,000 \mathrm{lb} / \mathrm{in}^{2}$ and $N=3,500 \mathrm{rpm}$, then a 300 -percent increase in viscosity at $210^{\circ} \mathrm{F}$, as indicated by the values given in table 1, would provide a 65 -percent increase in the factor of safety; but at normal operating conditions this increase in viscosity would result in a 33-percent increase in frictional horsepower and a $25^{\circ} \mathrm{F}$ rise in the operating temperature of the bearing.

TABLE 1.-Data showing viscosities at $100^{\circ} \mathrm{F}$ and $210^{\circ} \mathrm{F}$ and permissible pressures at $3,500 \mathrm{rpm}$

[Oils $A, B, C$, and $D, 2 \times 1 \frac{1}{4}$ in. test bearings, ambient temperature $80^{\circ} \mathrm{F}$.]

\begin{tabular}{|c|c|c|c|}
\hline Oil & $\begin{array}{l}\text { Viscosity at } \\
100^{\circ} \mathrm{F}\end{array}$ & $\begin{array}{c}\text { Viscosity at } \\
210^{\circ} \mathrm{F}\end{array}$ & $\begin{array}{c}\text { Permissible } \\
\text { pressures at } \\
3,500 \mathrm{rpm}\end{array}$ \\
\hline $\begin{array}{l}A \\
D \\
B \\
B\end{array}$ & $\begin{array}{c}\text { Centipoises } \\
335 \\
254 \\
108 \\
36.7\end{array}$ & $\begin{array}{r}\text { Centipoises } \\
21.8 \\
18.2 \\
10.3 \\
5.4\end{array}$ & $\begin{array}{l}L b / \text { in }^{2} \\
\quad 3,800 \\
3,600 \\
2,900 \\
2,300\end{array}$ \\
\hline \multicolumn{4}{|c|}{ Comparative ratios, oil $C$ as a basis } \\
\hline $\begin{array}{l}A / C \\
D / C \\
B / C \\
C / C\end{array}$ & $\begin{array}{l}9.1 \\
7.0 \\
2.9 \\
1\end{array}$ & $\begin{array}{l}4.0 \\
3.4 \\
1.9 \\
1\end{array}$ & $\begin{array}{l}1.65 \\
1.56 \\
1.26 \\
1\end{array}$ \\
\hline
\end{tabular}

The effect of changes in viscosity index is shown in Figure 7. These curves indicate the load-carrying characteristics of the bearing when using oils $A, B$, and $C$ of figure 6 in comparison with three oils $A^{\prime}, B^{\prime}$, and $C^{\prime}$ of the same respective viscosities at specification temperature but having a different viscosity index. From these curves it is seen that at the higher speeds a reduction in viscosity index in general reduces the permissible loads, the average reduction caused by a change from 98 viscosity index to 0 viscosity index being about 7 percent at $2,000 \mathrm{rpm}$ and 10 percent at 4,000 rpm.

The viscosities of $A$ and $A^{\prime}$ are specified at $210^{\circ} \mathrm{F}$, whereas those for $B, B^{\prime}, C$, and $C^{\prime}$ are at $130^{\circ} \mathrm{F}$. The effect of this difference in specified temperature of test is shown by the intersection points on the three pairs of curves, the $A-A^{\prime}$ intersection occurring at a higher speed than the $B-B^{\prime}$ and $C-C^{\prime}$ intersections. A comparison of curve $A^{\prime}$ in figure 7 and $D$ in figure 6 indicates that in the higher speed ranges the effect produced by a change from a 98 viscosity index to a 0 viscosity index is of the same order of magnitude as the effect produced by a change from the upper to the lower limits of viscosity of a SAE 60 oil with a 98 viscosity index.

The calculated viscosity values for each oil at the various temperatures were obtained by the use of Cragoe's $L^{\prime}$ relation [8] between viscosity and temperature.

The effect of pressure on viscosity has not been explicitly introduced in deriving these curves. In this connection it should be noted that the experimental determination of $K_{1}$, the limiting value of $Z N / P$, includes the effect of change of viscosity with pressure for the conditions covered. An estimate of the probable effects under other conditions can be made using the data available. Such a correction 
based on the correlation of viscosity-pressure data by Cragoe [8] indicates a possible reduction in the permissible pressures for oil $C$ of about 15 percent in the normal speed range. It is believed, however, that for practical purposes it would be preferable to evaluate such

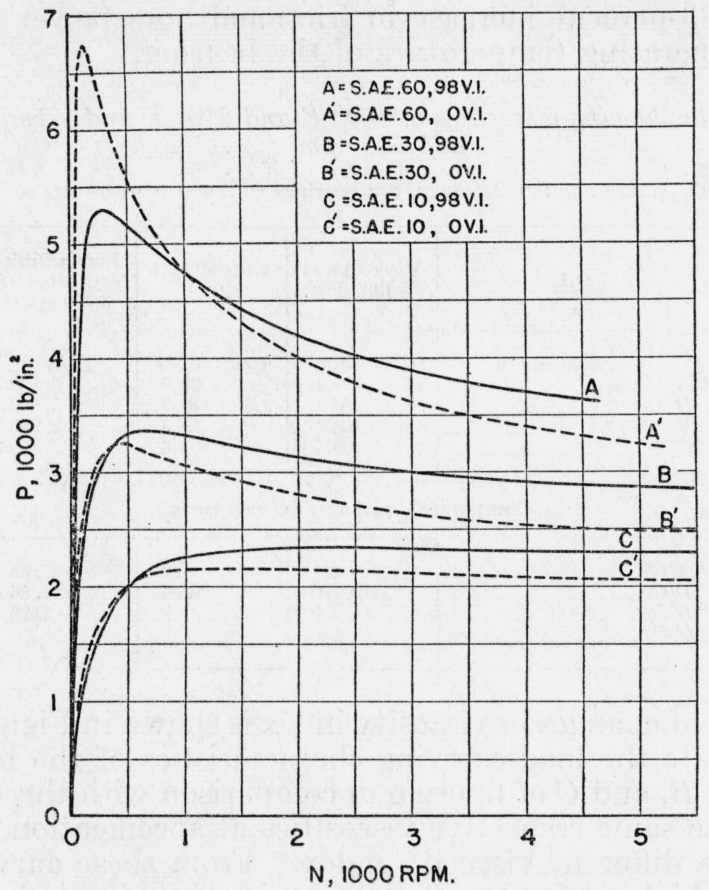

Figdre 7.-Curves showing effect of change in viscosity index on permissıble pressures at various speeds.

$2 \times 1 \frac{13}{4}$ in. test bearings; ambient temperature, $80^{\circ} \mathrm{F}$.

possible effects by experimentally determining their influence upon the value of $K_{1}$.

\section{EFFECTS OF CHANGES IN CRITICAL ZN/P VALUE}

The particular value of $Z N / P$ at the point of minimum $f$ obtained in the tests with these bearings is not necessarily characteristic of all journal bearings under all conditions. Experimental data indicate that this point may cover a fairly wide range of values of $Z N / P$, depending upon the frictional characteristics of the bearing metal, the machining of the bore, the amount of running in, the oiliness of the lubricant, and its viscosity-pressure characteristics. Other factors that may be significant are the clearance and length of the bearing, the manner in which the load is applied, and the method used to supply oil to the bearing.

The effects of a change in the critical value of $Z N / P$ are given in figure 8. Curves $A, B$, and $C$ represent respectively the load-carrying capacities of a bearing when using oils $A, B$, and $C$ previously mentioned, for which the critical value of $Z N / P$ is 4.6 , whereas $A^{\prime}, B^{\prime}$, 
and $C^{\prime}$ represent the respective load-carrying capacities of the bearing when the critical value of $Z N / P$ is changed to 3.5. From these curves it is seen that any factor tending to lower the critical $Z N / P$ value, such as the use of an oil of higher oiliness or a bearing metal giving lower friction, will tend to increase the load-carrying capacity pro-

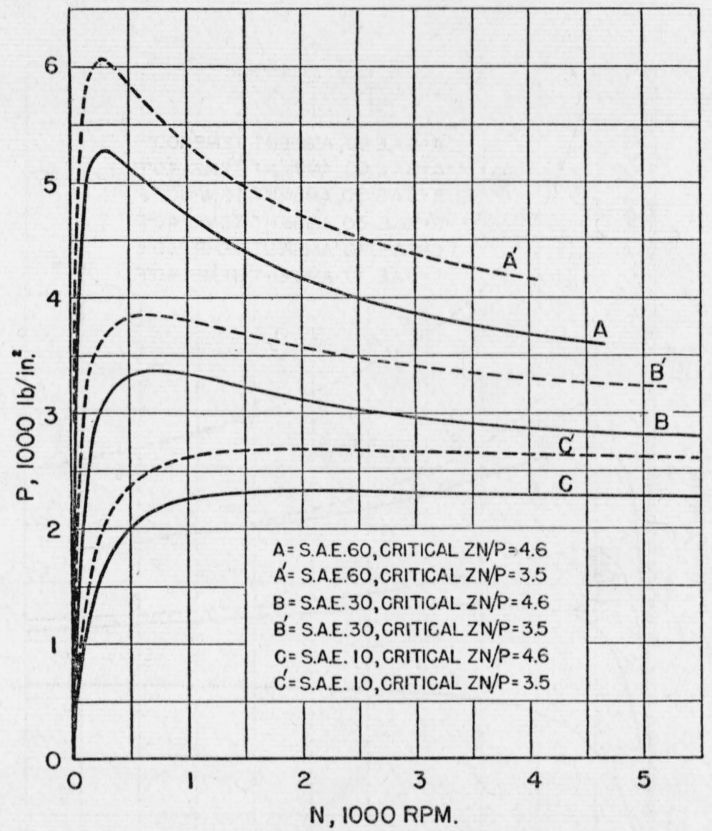

FIGURE 8.-Curves showing effect of change in critical value of $Z N / P$ on permissible pressures at various speeds for oils of different viscosity.

$2 \times 1 \frac{1}{4}$ in. test bearings; ambient temperature, $80^{\circ} \mathrm{F}$.

vided such a change does not affect other pertinent factors. In the higher speed ranges with these particular curves, the load-carrying capacity at a constant speed is approximately inversely proportional to the square root of the critical $Z N / P$ value. Inspection of eq 7 also indicates this relationship if $P$ is practically independent of $N$, which is true at the higher speeds.

\section{EFFECTS OF CHANGES IN AMBIENT TEMPERATURE}

Analysis of eq 4 indicates that the ambient temperature may have marked effects upon the operating characteristics of the bearing, since a change in ambient temperature will change the operating temperature and hence the value of $Z$ for a given temperature rise $\Delta T$.

Curves representing the load-carrying capacity of the test bearing under ambient temperature conditions typical of summer and winter operation are given in figure 9 . Curves $A, B$, and $C$ represent respectively the load-carrying capacity for oils $A, B$, and $C$ when the ambient temperature is $100^{\circ} F$, and curves $A^{\prime}, B,^{\prime}$ and $C^{\prime}$ when the ambient temperature is $40^{\circ} \mathrm{F}$. From these curves it is seen that with this bearing a change in ambient temperature from $100^{\circ} \mathrm{F}$ to $40^{\circ} \mathrm{F}$ 
is approximately the same in its effects on the load-carrying capacity of this bearing as a change in SAE numbers from 10 to 30 or from 30 to 60 .

Although this is not necessarily significant because of differences in conditions in the two cases, it is of interest that these results are in fair agreement with the usual practice in the lubrication of automobile engines.

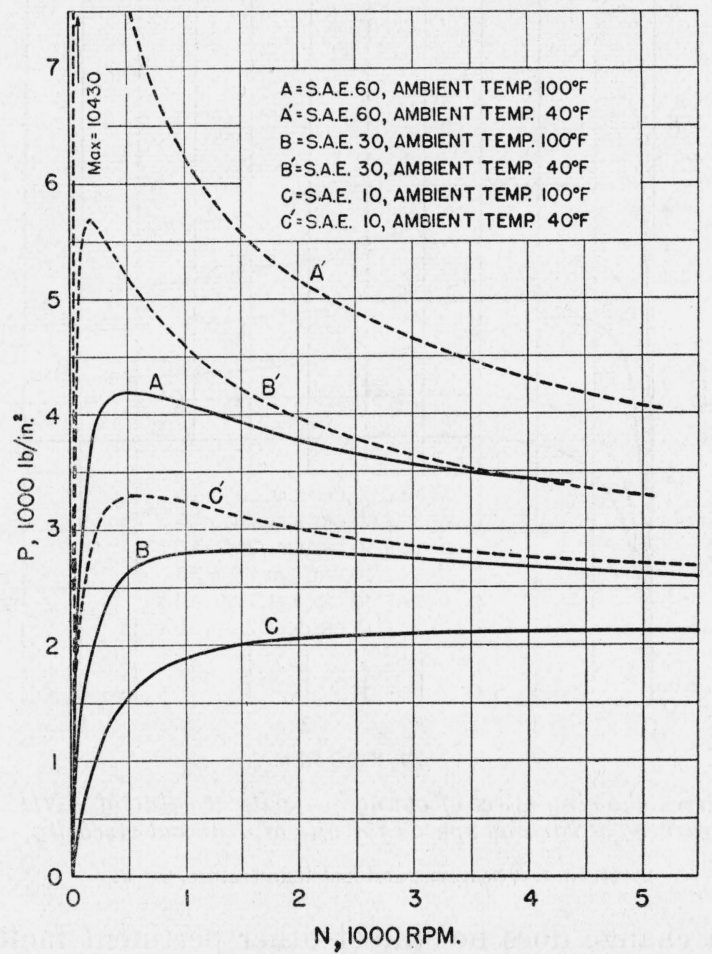

Frgure 9.-Curves showing effect of change in ambient temperature on permissible pressures at various speeds for oils of different viscosity.

$2 \times 11 / 4$ in. test bearings.

\section{EFFECTS OF CHANGES IN HEAT-DISSIPATION CHARACTERISTICS}

The data obtained in the tests with these bearings indicate that the heat-dissipation characteristics of the apparatus were probably representative of installations where the heat dissipation is relatively high. Evidence of this is given by the value of 1.65 obtained for the exponent $a$. This value is higher than might be expected from consideration of radiation, conduction, and natural convection, and is probably caused by a relatively large amount of heat being carried from the system by the lubricating oil.

Of the available published data on the heat-dissipation of bearings, a paper by Karelitz [2] deals with oil-ring bearings - a type of installation probably tending toward the lower range of heat-dissipation 
characteristics, since practically all the heat must be dissipated by the bearing housing. A comparison of the load-carrying capacity curves for these two installations, therefore, might give some idea as to the probable range of effects on bearing performance obtainable with various installations having different heat-dissipation characteristics.

Such a comparison is given in figure 10. Curve $A$ represents the load-carrying capacity of the bearing when using oil $A$ and where the

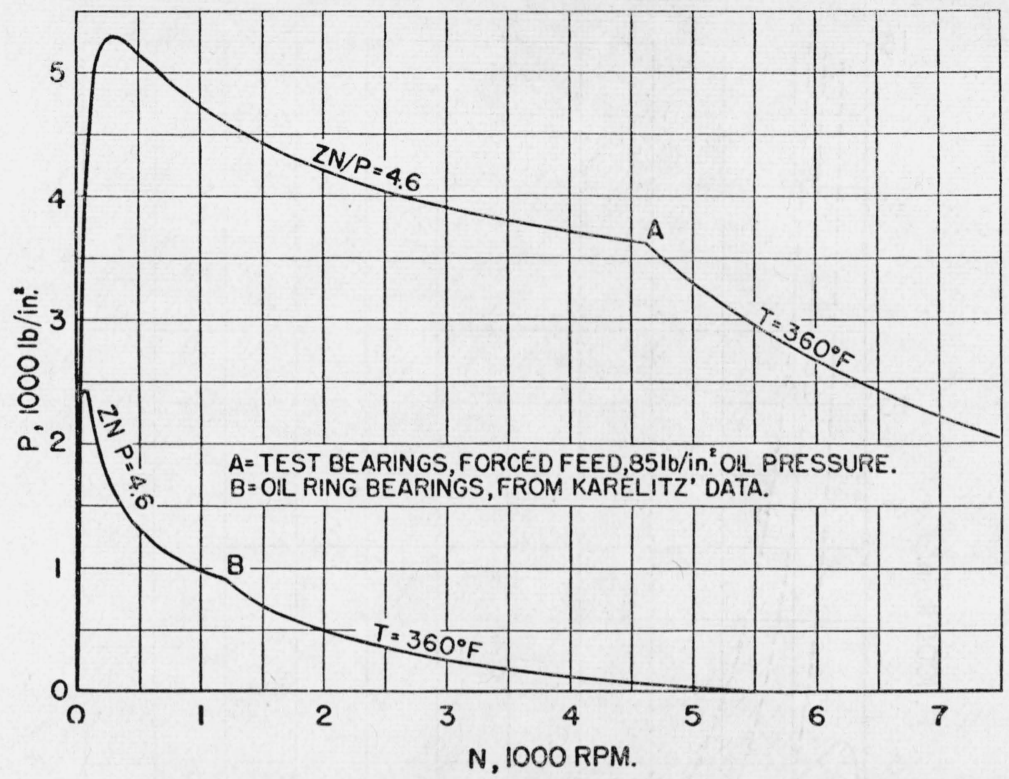

Fistine 10.-Curves showing effect of change in heat-dissipation characteristics on permissitle loads at various speeds.

$2 \times 114$ in. bearings; ambient temperature, $80^{\circ} \mathrm{F}$; lubricant, aviation oil $124.4 \mathrm{sec} \mathrm{SUV}$ at $210^{\circ} \mathrm{F}, 98 \mathrm{VI}$ (SAE 60 )

heat-dissipation constants are $U=7.38$ and $a=1.65$ as in these tests, whereas curve $B$ represents the load-carrying capacity of the same bearing using the same oil but with the heat-dissipation constants changed to $U=18.4$ and $a=1$, all other factors remaining the same. The latter values of $U$ and $a$ are interpreted from the heat-dissipation data for still air given by Karelitz. Curve $B$ is, of course, based solely upon the question of heat dissipation and does not take into account limiting speeds for satisfactory oil-ring operation. From these two curves it will be noted that the effect of the given change in heatdissipation characteristics is of much greater magnitude than the effects of changes of any of the other factors previously discussed.

A comparison of the operating characteristics of the bearing under the two conditions of heat dissipation may be obtained from typical temperature-speed and horsepower-speed curves obtained from the lines of constant temperature. For brevity, these have been omitted in this case and also in the discussions pertaining to viscosity index and ambient temperature. 


\section{COMPARISON WITH PRESSURE-VELOCITY (PV) RELATION}

In the foregoing discussion, certain indications have been pointed out as to the limitations of the hydrodynamic relations for providing complete information on the operating characteristics of a bearing unless thermal effects are also taken into account. It might be of interest, therefore, to consider the limitations on the use of relations

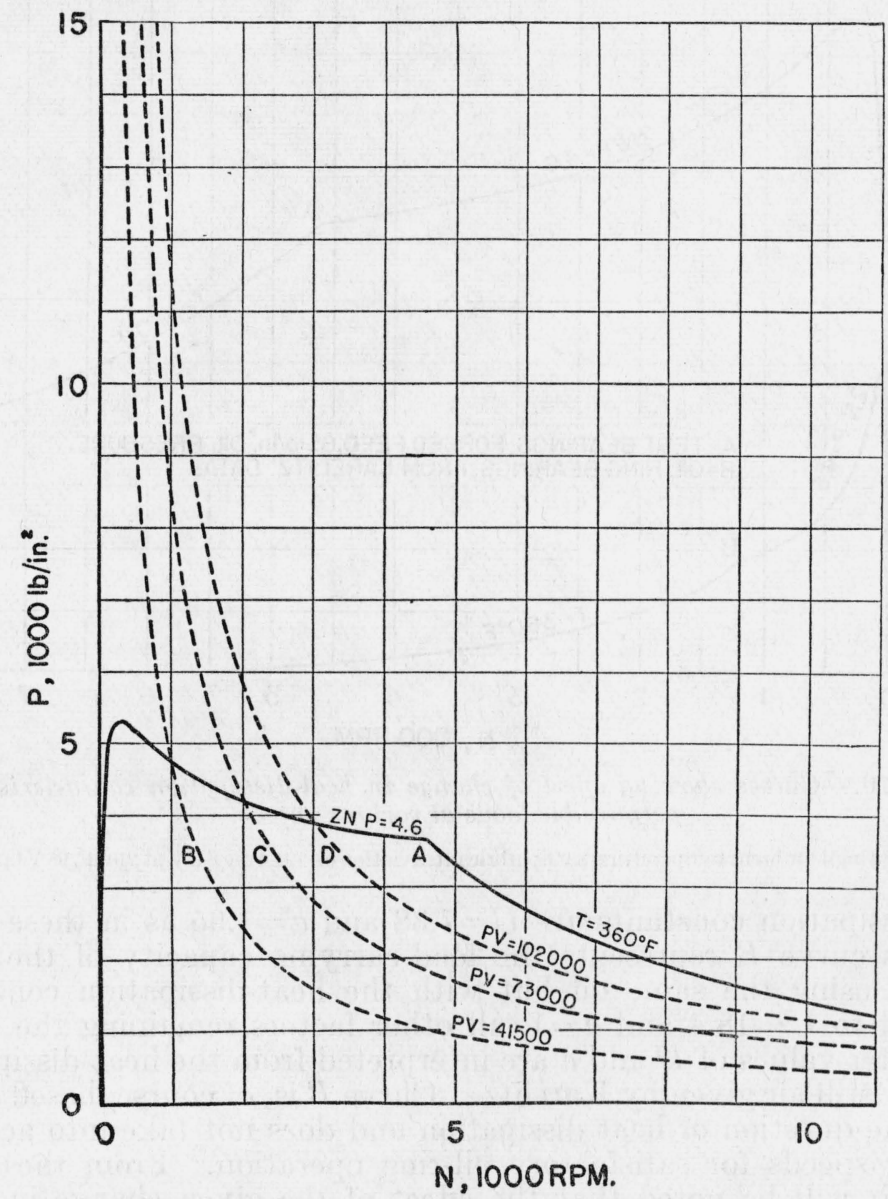

FIgURE 11.-Comparison between curves based on combined hydrodynamic and thermodynamic considerations and curves based on $P V$ relation.

$2 \times 1 \frac{144}{4}$ in. bearings; ambient temperature, $80^{\circ} \mathrm{F}$; l ubricant, aviation oil $124.4 \mathrm{sec}$ SUV at $210^{\circ} \mathrm{F}, 98 \mathrm{VI}$ (SAE 60 .)

based on thermal effects without taking into account the hydrodynamics of the film. Such a criterion, namely, that the product of the pressure by the surface velocity of the journal shall not exceed some fixed value ( $P V=\mathrm{a}$ constant), has been used to a considerable extent as a basis for determining safe operating limits. A comparison of the permissible pressures based on the $P V$ method and those based on the method combining hydrodynamic and thermal considerations 
is given in figure 11. Curve $A$ represents the permissible pressures as determined by eq 7,8 , and 10 , and curves $B, C$, and $D$, represent values of $P V$ equal to $41,500,73,000$, and 102,000, respectively, when $V$ is expressed in feet per second.

From this figure it is at once obvious that the relation $P V$ equals a constant does not provide a true criterion as to the limits of stable lubrication for these particular bearings under the test conditions, since the three values represented by the curves are approximately those at which the bearings were operating when the boundary between stable and unstable lubrication was reached at speeds of $1,000,2,000$, and $3,000 \mathrm{rpm}$, respectively. Thus in the particular range of operation covered by these tests, the limiting $P V$ value as determined by experiment is nearly proportional to $V$ instead of being a constant. In this connection it should be noted that in the bearing tests the indication as to when the bearing reached the unstable region was very definite. At loads where the operation was in the stable region, the frictional torque decreased as the temperature increased and usually in a few minutes the bearings would come to equilibrium with torque and temperature remaining practically constant. When the load was great enough to reach the unstable region, however, both torque and temperature increased, and the rate of increase was so rapid that it was necessary to install an automatic load release to safeguard the bearings.

The curves in figure 11 indicate that permissible loads from the $P V$ relation are greater in the low-speed range and smaller in the highspeed range than the permissible loads established by eq 7, 8, and 10 . This possibly indicates a reason why certain installations designed on the basis of the $P V$ relation have been used successfully, since the general trend of development has been toward higher speeds and the $P V$ relation tends toward an increase in factor of safety with increase in speed over the normal speed range.

\section{APPLICATION OF METHOD TO AUTOMOTIVE-ENGINE BEARINGS}

Probably one of the chief reasons for the lack of information regarding the heat-dissipation characteristics of various bearing installations is the difficulty in obtaining representative data. A number of installations involve complicated mechanisms where factors governing bearing operation are influenced by other entirely independent factors. It is believed, however, that in some of these cases data may be obtained which, when used in conjunction with the method for determining load-carrying capacity, will provide approximations of reasonable accuracy.

In the case of automotive-engine bearings, for example, such an approximation can be obtained by measuring bearing temperatures for various speeds at various power outputs. These data can then be correlated by use of eq 4 . In this equation all of the factors on the left pertaining to the rate of heat generation may be evaluated either by direct measurement or by assumptions based on present data. Representative values for $U$ and $a$ may therefore be computed from curves obtained by plotting the values for the rate of heat generation against the corresponding values for $\Delta T$, the temperature rise. Although it is probable that no single curve would be representative 
for all conditions, the values representing the most adverse case can be used in eq 7,8 , and 10 to obtain load-carrying capacity and other performance curves. While too little information is available regarding the factors involved to obtain other than a rough approximation, it should be noted that the same assumptions used to determine $U$ and $a$ are also used in eq 7,8, and 10; hence the effects of some of the inaccuracies may be reduced.

\section{CONCLUSION}

In the above discussion a method is suggested for the application of friction and heat-dissipation data to the determination of the loadcarrying capacity of a journal bearing when operating with a lubricant of known characteristics. It may be used to estimate the effects upon the operating characteristics of the bearing of changes in a number of the various factors involved. It also provides a means for correlation of data in bearing installations where conditions are such that factors affecting bearing operation cannot readily be determined. The two fundamental concepts upon which the method is based are the establishment of a minimum safe limit for the generalized operating variable $Z N / P$ and a maximum safe limit for the operating temperature. With the data available at the present time, it will provide only an approximate measure of bearing capacity. Steps necessary for a more rigorous application are a comprehensive study of the frictional characteristics of journal bearings at the lower values of $Z N / P$ and a complete investigation of the heat-dissipation characteristics of various bearing installations.

\section{REFERENCES}

[1] S. A. McKee, Journal-bearing design as related to maximum loads, speeds and operating temperatures, J. Research NBS 19, 457 (1937) RP1037; General discussion on lubrication, Proc. Inst. Mech. Engrs. (London) 1, 179-186 (1937).

[2] G. B. Karelitz, Performance of oil-ring bearings, Trans. Am. Soc. Mech. Engrs. APM-52-5, 57-70 (1930).

[3] M. D. Hersey, Laws of lubrication of journal bearings, Trans. Am. Soc. Mech. Engrs. 37, 167 (1915).

[4] R. E. Wilson and D. P. Barnard, The mechanism of lubrication, Trans. Soc. Auto. Engrs. 17, pt. 1, 203 (1922).

[5] S. A. McKee and T. R. McKee, Friction of journal bearings as influenced by clearance and length, Trans. Am. Soc. Mech. Engrs. APM-51-15, 161-171 (1929).

[6] M. D. Hersey, Theory of Lubrication (John Wiley \& Sons, Inc., London and New York, 1936).

[7] D. P. Barnard, A possible criterion for bearing temperature stresses, SAE Journal $30,192(1932)$.

[8] C. S. Cragoe, Changes in the viscosity of liquids with temperature, pressure, and composition, Proc. World Petroleum Congr., London, 2, 529-541 (1933).

Washington, February 20, 1940. 